САБИРОВА Нагима Садыковна - кандидат политических наук, Московский государственный областной университет (141014, Россия, Московская обл., г. Мытищи, ул. Веры Волошиной, 24; snagima95@gmail.com)

\title{
ФЕНОМЕН ПАТЕРНАЛИЗМА В ПОЛИТИЧЕСКОЙ КУЛЬТУРЕ РОССИИ
}

\begin{abstract}
Аннотация. В данной статье рассматривается явление патернализма в политической культуре России, который имеет особенную форму влияния на обустройство отношений между властью и гражданами. Корни такой модели связи между обществом и властью многие исследователи находят в традиционнопатриархальной культуре, сложившейся в многовековой истории России. Автор приходит к выводу, что в настоящее время патерналистские настроения практически малозаметны; патернализм утратил свою системность в процессе социализации современного общества в рамках становления демократических и правовых принципов, выражающихся в общем сознании всех граждан как представителей политической культуры страны.
\end{abstract}

Ключевые слова: патернализм, политическая культура, патриархально-традиционная культура, иерархия, государство, власть, идеология, демократия, партия, правовая система, гражданское общество

Я вление патернализма занимает особое место в политической культуре России. С научной точки зрения политический патернализм (от лат. paterотец) означает определенную систему отношений между властью и гражданами, при которой властные структуры обеспечивают потребности последних. В обмен на это общество позволяет правительству осуществлять управление государством в своих интересах. Таким образом, конструкция патернализма представляется с позиции «вся власть и забота в руках государства», которая отражает законсервированное общество, объединенное кодексом этики, продиктованным властью. Очевидно, что подобная система власти не отвечает демократическим принципам и не соответствует правовым идеалам современной России, какой она представлена в Конституции РФ.

Тем не менее патерналистская традиция и сегодня не изжила себя в Российском государстве. Как отмечает Т.Ф. Ермоленко, корни патерналистской традиции лежат в русской культуре, связанной с историческим прошлым [Ермоленко 1998].

В частности, большую роль в аграрном обществе играла патриархальная семья, которая по тем временам могла состоять из нескольких десятков человек, и авторитет главы в ней был непререкаемым. Он был не только добытчиком и защитником для всех членов семьи - за ним закреплялись функции поощрения и наказания, контроль за соблюдением нравственных норм. Налицо властные формы отношений авторитарного типа в первичной ячейке общества [Баранов 2016]. Следовательно, в этом случае за домочадцами оставались только функции исполнения. Подобный традиционно-патриархальный уклад жизни, как полагают многие исследователи, впоследствии отпечатался в политической незрелости индивида. С точки зрения Н.А. Баранова, в такой ситуации человек не испытывает потребности чувствовать себя личностью, он перекладывает ответственность за свою судьбу на семью, государство, власть, уходит от индивидуальной ответственности, а значит и от свободы. Автор подчеркивает влияние природно-климатических условий, закрепивших патерналистские черты в русской крестьянской культуре, а также фактора религии. Православие осветило эти отношения авторитетом церкви. Таким образом, патернализм стал 
культурным архетипом, закрепленным в российской ментальности и политической культуре [Баранов 2016].

В теории официальной народности, разработанной в середине 1830-х гг., министр народного просвещения С.С. Уваров неосознанно отобразил политическую культуру России того времени. В его триаде есть место и патернализму не только в контексте политической культуры, но и в других аспектах жизни, что, собственно, отображает политический режим и государственный строй самодержавной России. Очевидно, что проект С.С. Уварова не представлялся каким-либо либеральным предложением для обдумывания, а был наполнен принципами абсолютного самодержавия и видением патриархальной иерархии общества. Автор указывал каждому слою населения Российской империи его социальную и в целом жизненную нишу, тогда как политическая ниша полностью отсутствовала, кроме требования служить верой и правдой батюшкецарю, который представлялся добрым, праведным защитником и заботливым отцом народа. Это не только внутри семьи, но и на государственном уровне невольно закрепляло особую ментальность в российском сознании [Баранов 2016].

В тот период не только крестьяне были отстранены от мирной политической жизни страны, но и дворяне, невзирая на все свои привилегии, были от нее отчуждены, за исключением военных и чиновников, несших службу царю. То есть, по сути, каждый занимался своим делом: крестьяне пахали землю, дворяне посещали балы, духовенство молилось, чиновники служили, военные защищали, царь руководил. Этот уклад жизни в принципе не вызывал никаких инициатив и личностных притязаний. Конечно, можно вспомнить дворцовые перевороты, крестьянские войны, восстание декабристов, революции. Россия всегда была богата яркими личностями, которые влияли на исторические процессы государственного преобразования и общественные движения. Последствия потрясений не могли не оставить отпечаток в сознании людей.

Современное общество выработало ряд форм и механизмов для защиты своих прав и свобод. При рассмотрении патернализма с его исторического проявления в России очевидно, что он не мог не проявиться и в других государствах, т.к. эволюция человеческого общежития и государства проходит традиционно-патриархальный путь. В дальнейшем благодаря инициативным гражданам и сопутствующей форме власти на смену патернализму приходит более перспективная модель - гражданское общество. Институты гражданского общества - это организации, в которых индивид может реализовать свои личные, профессиональные, социальные интересы и потребности. Развитие гражданского общества в России сегодня наиболее актуально. Но перспектива его становления, следует признать, пока зависит от государства.

В советский период традиция патернализма также была ярко выражена. Органы партийной власти через определенные идеологические организации осуществляли функции опеки, надзора, поощрения и наказания граждан, руководствуясь Кодексом строителя коммунизма. Тем не менее нельзя утверждать, что советские граждане были вовсе лишены инициативы и личностных подходов, которые часто выражались в активном желании пополнить ряды пионерии, комсомола, передовиков труда. Отсутствие идеологического плюрализма не было для большинства трагедией, т.к. советская идеология соответствовала их взглядам. По сути, советский патернализм представлял собой лабиринт, в котором сложно определить, где его начало и где конец.

Анализируя систему российской власти, М. Снеговая находит во всех ее аспектах элементы патернализма. Причина, как она видит, кроется в совет- 
ской системе, которая законсервировала патерналистский уклад крестьянской общины, распространив его на экономику и политику за счет системы распределения социальных благ через предприятия. Эта структура сделала лояльность (а не успешность, эффективность, инициативность) подчиненных критерием распределения благ. Эта система убивала личную инициативу и воспроизводила традиционалистскую культуру. С переходом к рыночной экономике система патерналистских отношений стала постепенно распадаться, но по-прежнему сохраняется на многих предприятиях и в госсекторе [Снеговая 2015].

Таким образом, российский патернализм имеет свои корни, которые кроются в истории формирования общества и государства. Дальнейшие его проявления обозначились понятиями времени, но в каждый период новой формации патернализм сохраняет свое существование как ген стагнации и образует поведенческий стереотип, пронизывающий политическую культуру страны. Следует согласиться, что и сегодня патерналистические настроения актуальны, и это не потому, как пишут многие авторы, что население несамостоятельно и не ответственно за свою судьбу. Подобные заявления абсолютно беспочвенны. Российский народ по своей природе и ментальности, бесспорно, уникален и велик и не может быть безвольным. Россия - огромная страна, и по укладу жизни, как социальной, так и экономической, а также по отношению к власти и политике внутри нее у каждого складываются свои взгляды. Проблема кроется в том, что российский патернализм находится в пограничном состоянии, как механизм, который в скором времени придет в негодность. Большая часть людей среднего и старшего возраста имеют свои взгляды в отношении государства. Как бы то ни было, властные структуры владеют прямыми полномочиями и компетентностью в решениях социальных, экономических, политических проблем. И здесь ошибочно винить граждан за гипертрофированность их надежд на верховную власть и стремление перекладывать на нее свою судьбу. Скорее все наоборот - требования общества выражаются не в просьбе опеки со стороны государства, а в изменении их качества жизни, что подразумевает, в отличие от поведенческого патернализма, другой характер и категорию видения.

В любом государстве, передовом или не очень, нет как таковой изоляции власти от общества, т.к. именно общество владеет управленческой системой власти, от которой в целом зависит его жизнь, в т.ч. политическая. Также среди россиян есть ностальгирующие по советской власти: это в большинстве случаев довольно зрелые люди, которые имеют свое собственное мнение по поводу власти и ее оценки. Исключение составляют и те, кто равнодушен к политике и каким-либо государственным делам: это определенная категория людей, которым чуждо участие в общественно-политической жизни страны.

По конституционному законодательству Россия является социальным государством, и один из его важнейших признаков - высокий жизненный уровень населения. В этом случае государство не ограничивает свои полномочия только предоставлением условий для развития свободного предпринимательства, но и выплачивает различные пособия - по безработице, инвалидности; предоставляет льготы на жилье малоимущим, многодетным и т.д. Важность этой развивающейся социальной политики заключается в том, что ее концепция имеет свои приоритетные функции обеспечения социальных и экономических прав человека, что соответствует статусу социального государства, а не представляется очередным синдромом государственного патернализма.

Таким образом, каждый гражданин соответствующего статуса имеет полное право подавать заявку и пользоваться предоставляемыми материальными суб- 
сидиями государства. Подобная практика развита в странах с успешной социальной политикой, таких как Германия, Норвегия, Швейцария и др.

Существование патернализма в России кроется в большом социальном разрыве, который способствует таким явлениям, как взятки, блат, превышение должностных полномочий. Их искоренение возможно при стабилизации экономики, распределения благ и при четко налаженной правовой системе в качестве защитника морально-правовых норм человека и гражданина.

Модернизация России после распада СССР имеет основание быть длительной, а ее ускорение зависит от многих факторов, одним из которых является показатель политической культуры, стремящейся стать демократической категорией. В последние годы наблюдается активизация участия всех слоев населения России в политической жизни страны, в т.ч., что немаловажно, и среди молодежи, т.к. за ней настоящее и будущее. Однако патерналистские настроения наблюдаются и среди молодых. Аналитик Г.В. Радзинский пришел к следующему выводу: молодежь не отказывается от патерналистских стратегий пассивного ожидания и выживания (будут жить на пособия по безработице, вести экономный образ жизни, обращаться за помощью в благотворительные организации, в органы соцзащиты) [Радзинский 2014].

Социальное государство, каковым является и Россия, предоставляет определенные условия для жизни граждан. В России проживают 146 млн чел., а это означает многообразие характерных черт и пониманий. Какой-то процент населения всегда будет не только нуждаться в помощи, но и проявлять пассивность, безразличие, отстраненность. При этом молодые люди более уязвимы по причине отсутствия зрелости, опыта и знаний. Тем не менее большая часть российской молодежи стремится получить достойное образование и реализовать свои способности. Также они связывают свои гражданские и личные ориентиры с демократическими и правовыми ценностями.

Таким образом, патернализм как феномен политической культуры в России малозаметен, поскольку он утратил свою системность в процессе социализации современного общества, которое в последние годы более активно участвует в политической жизни страны, обладает ориентирами в аспектах ее обустройства и знанием своих функций по отношению к ней.

\section{Список литературы}

Баранов Н.А. 2016. Политическая культура России: традиции и современность: лекция 18. Доступ: https://www.nicbar.ru/sgp/36-goyard-elated-nsiz.html (проверено 03.07.2021).

Ермоленко Т.Ф. 1998. Патернализм в политической культуре России. Российская историческая политология. Курс лекций: учебное пособие (отв. ред. С.А. Кислицын). Ростов н/Д: Феникс. С. 223-234.

Радзинский Г.В. 2014. Молодежь: устойчивость патерналистского синдрома и перспективы его преодоления. - Вестник ПНИПУ. Социально-экономические науки. № 4(25). С. 60-65.

Снеговая М. 2015. Патернализм как часть непродуктивной культуры. Доступ: https://www.vedomosti.ru/opinion/articles/2015/04/16/paternalizm-kak-chastneproduktivnoi-kulturi (проверено 03.07.2021). 
SABIROVA Nagima Sadykovna, Cand.Sci. (Pol.Sci.), Moscow State Regional University (24 Very Voloshinoi St, Mytishchi, Moscow Region, Russia, 141014; email: snagima95@gmail.com)

\title{
THE PHENOMENON OF PATERNALISM IN THE POLITICAL CULTURE OF RUSSIA
}

\begin{abstract}
The article examines the phenomenon of paternalism in the political culture of Russia, which has its own special form of influence on the arrangement of relations between the authorities and citizens. It lies in the fact that the power structures provide for the needs of their subjects, and in return for this, they provide government bodies to manage the state in their own interests. Many researchers find the roots of this model of communication between society and power in the traditional patriarchal culture that has developed in the centuries-old history of Russia. In general, the author concludes, that at present paternalistic sentiments are practically invisible, since paternalism has lost its systemic character in the process of socialization of modern society within the framework of the formation of democratic and legal principles expressed in the common consciousness of all citizens as representatives of the country's political culture.
\end{abstract}

Keywords: paternalism, political culture, patriarchal-traditional culture, hierarchy, state, power, ideology, democracy, party, legal system, civil society

КЛИМАШЕВСКАЯ Ольга Викторовна - кандидат политических наук, доцент Московского авиационного института (национальный исследовательский университет) (125993, Россия, г. Москва, Волоколамское ш., 4; Klimawevskaya@yandex.ru)

\section{ПРОБЛЕМА КЛАССИФИКАЦИИ АДМИНИСТРАТИВНЫХ ПРАВОНАРУШЕНИЙ В ПРАВОПРИМЕНИТЕЛЬНОЙ ДЕЯТЕЛЬНОСТИ}

\begin{abstract}
Аннотация. Целью настоящей статьи является анализ классификации административных правонарушений в правоприменительной деятельности с позиции ее соотношения с уголовным правом. Отправной точкой является генезис понятия административного правонарушения, изменение терминологии в данной области и влияние этих преобразований на судебную практику.

Ключевые слова: административное правонарушение, административный проступок, формальный состав, материальный состав, длящиеся правонарушения, оконченные правонарушения, продолжаемые правонарушения
\end{abstract}

дминистративные правонарушения - это одно из базовых понятий инсти-
дтута административной ответственности. С принятием Кодекса РФ об
административных правонарушениях в 2001 г. изменилась терминология: если
раньше говорилось об административных проступках, то на сегодняшний день
речь идет об административных правонарушениях.
Принято считать, что изменение терминологии связано со сближением уго-
ловной и административной ответственности и лучше подчеркивает публич-
ность этих институтов. Официальное определение этого термина содержится
в Кодексе Российской Федерации об административных правонарушениях.
Согласно кодексу, под административным правонарушением подразуме-
вается противоправное виновное действие или бездействие физического и 